\title{
Determination of Dopamine in the Presence of Ascorbic Acid on Digitonin-Doped Coal Tar Pitch Carbonaceous Electrode
}

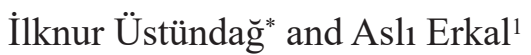 \\ Dumlupınar University, Faculty of Arts \& Science, Department of Physics, 43100 Kütahya, Turkey \\ ${ }^{1}$ Dumlupınar University, Faculty of Arts \& Science, Department of Chemistry, 43100 Kütahya, Turkey
}

(Received June 10, 2016; accepted September 1, 2016)

Keywords: digitonin, coal tar pitch, carbonaceous electrode, dopamine, differential pulse voltammetry

A novel carbonaceous material was prepared from a digitonin (DG)-doped coal tar pitch (CTP) with a tube furnace under nitrogen atmosphere. It was used as an electrode after mixing the material with an organic binder (resin). The new carbon electrode was denoted as CTP-DG. CTPDG was characterized by cyclic voltammetry (CV), infrared spectroscopy (IR), X-ray photoelectron spectroscopy (XPS), scanning electron microscopy (SEM), and X-ray diffraction (XRD). The electrode was used for the determination of dopamine (DA) by differential pulse voltammetry (DPV). It exhibits a linear response to DA in the range of $1-60 \mu \mathrm{M}$. The detection limit $(S / N=3)$ for DA is $80 \mathrm{nM}$. Satisfactory results were achieved for the determination of DA in human urine samples.

\section{Introduction}

Recently, carbonaceous materials (CMs) and their hybrids have been actively pursued as electrocatalysts for electrochemical studies. ${ }^{(1)}$ CMs such as glassy carbon (GC), ${ }^{(2)}$ vitreous carbon, ${ }^{(3)}$ pyrolyzed photoresist film (ppf)-coated substrates, ${ }^{(4)}$ carbon nanotubes, ${ }^{(5)}$ and graphene ${ }^{(6)}$ are very conductive surfaces as working electrodes. Currently, CMs with natural carbon matrices including products such as plant ${ }^{(7)}$ and animal ${ }^{(8)}$ sources are used as next-generation electrodes. In addition, some chemicals such as polysaccharides/osazones, ${ }^{(9)}$ and polymers ${ }^{(10)}$ are preferred as raw materials. In a previous study, ${ }^{(1)}$ an electrode material was synthesized from a prawn shell with enriched chitin under pyrolysis temperature. The material was used as an electrocatalyst for oxygen reduction reaction. In another study, ${ }^{(12)}$ carbonaceous foam was prepared for biofuel cells. Its electrochemical activity was determined using the catalytic current of a porous electrode that was 13-fold greater than that of a bare GC electrode. Lv et al. studied the carbonization of peanut shells..$^{(13)}$ The untreated and pretreated shells were pyrolyzed using a tubular furnace at $600{ }^{\circ} \mathrm{C}$. The carbonized materials were used as ultralong cycling anodes for lithium and sodium batteries.

Many researchers are still using conventional electrodes such as GC, carbon paste, gold, and platinum. CMs such as a coal tar pitch (CTP) and a CTP composite are not yet commonly used as electrode materials. They are quite an original research topic in electrochemistry and may be used, for example, as sensor templates, ${ }^{(14)}$ electronic device elements, ${ }^{(15)}$ heat exchangers, ${ }^{(16)}$ and supercapacitors. ${ }^{(17)}$ The CTP is a very low cost material ${ }^{(18)}$ for these studies and an excellent precursor for carbonaceous composites. ${ }^{(19)}$ It has high conductivity and stability, and a large surface 
area. ${ }^{(20)}$

The dopamine (DA) molecule is vital for the central and peripheral nervous systems. ${ }^{(21)}$ The determination of the DA molecule has great significance. DA, ascorbic acid (AA), and uric acid (UA) usually coexist in food and biological samples. ${ }^{(22)}$ Thus, the determination of DA in the presence of AA is very significant.

In this study, digitonin (DG), which is a kind of glycoside, was added into a CTP. The carbonized product was denoted as CTP-DG. The material was carbonized with a tube furnace at $1000{ }^{\circ} \mathrm{C}$ under inert $\mathrm{N}_{2}$ flow at a heating rate of $10^{\circ} \mathrm{C} / \mathrm{min}$ for a hold period of $1 \mathrm{~h}$. The carbonized solid was ground into fine powder in a planetary ball mill. The material was characterized by some techniques such as electrochemical, spectroscopic, and microscopic methods. It was used as an electrode material after mixing it with a resin as an organic binder. The electrode was used in the determination of DA by differential pulse voltammetry (DPV). The developed method was used for the determination of DA in real samples.

\section{Experimental Procedure}

All chemicals were of reagent grade and used without further purification. They were obtained from commercial suppliers such as Merck, Fluka, Sigma-Aldrich, and Riedel. The CTP was purchased from Orcan Asfalt ve Yalitim Urunleri Company (Tuzla-Istanbul, Turkey). Bare GC working electrodes were obtained from GC-20 (Tokai, Japan). CTP-DG, CTP, and GC electrodes were cleaned and polished on a microped (Buehler, Lake Bluff, IL, USA) with 100 and $50 \mathrm{nM}$ aluminum oxide suspensions (Baikowski, USA). Then, the polished carbon electrodes were sonicated with an ultrasonic bath (SK1200H ultrasonic cleaner, China) in ultrapure water (UPW, 18.2 $\mathrm{M} \Omega \mathrm{cm}$, Human Power 1+, South Korea) and in 1:1 (v/v) isopropyl alcohol (IPA)/acetonitrile $(\mathrm{MeCN})$ solutions for approximately $7 \mathrm{~min}$. Electrochemical measurements were performed using an Ivium CompactStat, (U.S.) electroanalyzer. All data were acquired with a triple-electrode system at room temperature $\left(25 \pm 1{ }^{\circ} \mathrm{C}\right)$ under a high-purity argon $(99.999 \%)$ atmosphere. A platinum wire was used as an auxiliary electrode. $\mathrm{Ag} / \mathrm{AgCl} / \mathrm{KCl}_{\text {(sat) }}$ and $\mathrm{Ag} / \mathrm{AgNO}_{3}(0.01 \mathrm{M})$ were used as reference electrodes for aqueous and nonaqueous media, respectively.

\subsection{Synthesis of carbonized CTP-DG}

CTP-DG was prepared with a DG-doped CTP. The amount of DG in the CTP was adjusted as $1 \%(\mathrm{w} /$ w). $10 \mathrm{~g}$ of the DG-added CTP composite was carbonized in a $\mathrm{N}_{2}$-atmosphere tube furnace (Protherm, Turkey) with a heating rate of $10{ }^{\circ} \mathrm{C} / \mathrm{min}$ to reach $1000{ }^{\circ} \mathrm{C}$. This was followed by the annealing of the materials at $1000{ }^{\circ} \mathrm{C}$ in $\mathrm{N}_{2}$ atmosphere for $1 \mathrm{~h}$. The black material transformed into metallic grey. The carbonized solid (CTP-DG) was ground into fine powder in a planetary ball mill PM100 (Retcsch, Germany). In addition, a pure CTP electrode was synthesized under the same conditions for comparison with the CTP-DG electrode.

A very small amount of "kamalak" resin (Cedrus libani A. Rich.) was sprayed in $2 \mathrm{~g}$ of CTP and CTP-DG powder. The moistened powders were pressed into pellets of $10 \mathrm{~mm}$ diameter. The disc pellets were dried with an oven at $55^{\circ} \mathrm{C}$ under vacuum. The electrodes were packed into the cavity of a politetrafloroetilen (Teflon) tube. The electrode surface area is $0.073 \mathrm{~cm}^{2}$ in the Teflon tube. Parts of the CTP-DG working electrode and cell system are shown in Fig. 1. 



Fig. 1. (Color online) Parts of (a) CTP-DG working electrode and (b) cell system.

\subsection{Characterization of $\mathrm{CM}$}

The CMs were characterized with ferrocene and ferricyanide/ferrocyanide redox probes by cyclic voltammetry (CV) and EIS techniques, respectively. All three electrodes (GC, CTP, and CTP-DG) were placed in the Teflon tube. Electrochemical results of the CTP-DG electrode were compared with those of the CTP and GC electrodes. The stability of the CTP-DG electrode was tested with ferrocene by $\mathrm{CV}$ when it was kept in an open atmosphere for $10 \mathrm{~d}$.

The infrared spectroscopy (IR) measurement of the CTP and CTP-DG electrodes was performed in a Bruker Tensor 27 (Germany) FT-IR spectrophotometer with a diamond-ATR accessory (Harrick Scientific, USA). X-ray diffraction (XRD) measurements of the CTP and CTP-DG electrodes were obtained with a Rigaku Miniflex (Japan) X-ray diffractometer. Scanning electron microscopy (SEM) images were obtained using a SEM system (Zeiss-Evo, Germany). X-ray photoelectron spectroscopy (XPS) data was obtained with an X-ray photoelectron spectrometer [PHI 5000, Versa Probe [ $\Phi$ ULVAC-PHI. Inc., Japan/USA) with monochrome $\mathrm{Al} \mathrm{K \alpha}$ radiation $(1486.6 \mathrm{eV}$ ] as an $\mathrm{X}$-ray anode and operated with $50 \mathrm{~W}$ at $10^{-7} \mathrm{~Pa}$.

\subsection{Calibration study of DA in aqueous media}

The electrocatalytic activities of the GC, CTP, and CTP-DG electrodes were determined via DPV. A comparison of DPVs of DA on all electrodes was carried out. CV studies of DA at various scan rates $(10$ to $300 \mathrm{mV} / \mathrm{s})$ were performed in $0.1 \mathrm{M}$ PBS $(p H=7)$. Various concentrations (1 to $60 \mu \mathrm{M})$ of DA standards in the presence of $5 \mathrm{mM} \mathrm{AA}$ were spiked into the cell. DPV results were recorded by positive scanning at a rate of $20 \mathrm{mV} \mathrm{s}^{-1}$, a pulse amplitude of $25 \mathrm{mV}$, a pulse rate of $0.5 \mathrm{~s}$, and a pulse width of $60 \mathrm{~ms}$ for a holding time of $2 \mathrm{~s}$. Calibration curves of DA were plotted at $25 \pm 1$ ${ }^{\circ} \mathrm{C}$. The limits of detection (LODs) of the developed method were calculated $(S / N=3)$. 


\subsection{Sample analysis}

The CTP-DG electrode was applied to the determination of DA in human urine samples. A 100 $\mu \mathrm{L}$ urine sample without any sample pretreatment was directly added into the electrolyte solution and analyzed by DPV. All measurements were repeated three times.

\section{Results and Discussion}

\subsection{Characterization of CTP-DG}

Cyclic voltammograms of $2 \mathrm{mM}$ ferrocene redox probes in 0.1 M TBATFB in MeCN on the GC, CTP, and CTP-DG electrodes are given in Fig. 2(a). The electron transfer rate of the redox probe is partially higher on the CTP-DG surface than on the CTP and GC surfaces [Fig. 2(a)]. The anodic peak currents of the redox probes on the GC, CTP, and CTP-DG electrodes were calculated as $39.2 \pm 2.3,50.3 \pm 2.7$, and $87.1 \pm 1.2 \mu \mathrm{A}$, respectively. The electrode stability of CTP-DG was tested with ferrocene by CV [Fig. 2(b)]. The electrode was kept in an open atmosphere for $10 \mathrm{~d}$. The anodic peak current of the CTP-DG electrode did not change even after $10 \mathrm{~d}$.

The electrode performance characteristics of the GC, CTP, and CTP-DG electrodes were investigated by EIS using a $2 \mathrm{mM} \mathrm{K}_{3} \mathrm{Fe}(\mathrm{CN})_{6} / \mathrm{K}_{4} \mathrm{Fe}(\mathrm{CN})_{6}$ redox probe in $0.1 \mathrm{M} \mathrm{KCl}$ media. The Nyquist plots of all the three electrodes are shown in Fig. 3. All Nyquist plots were fitted with a diffusion-controlled CPE equivalent electrical circuit. ${ }^{(23)}$ The charge transfer resistance (Rct) of redox probes was decreased using the CTP-DG electrode as in the cases of the GC and CTP electrodes. The electron transfer of the redox couple was accelerated on the CTP-DG electrode. The Rct values of the CTP-DG, GC, and CTP electrodes were fitted as 4.2, 6.4, and $5.7 \mathrm{k} \Omega$,

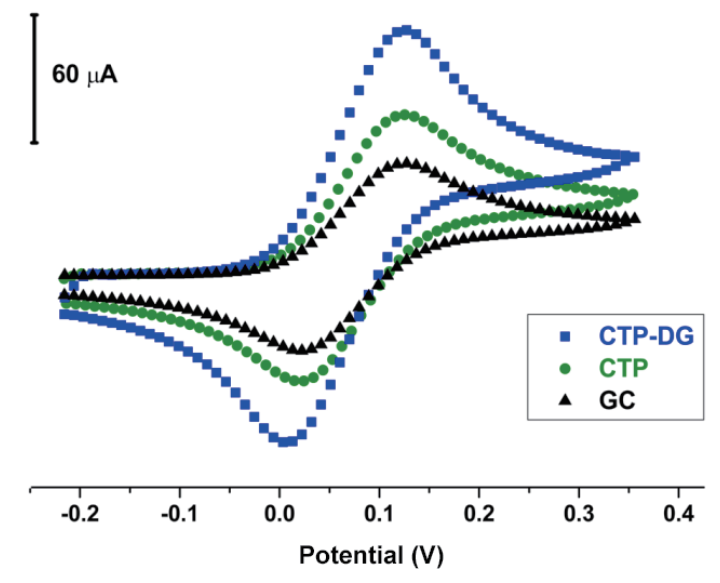

(a)

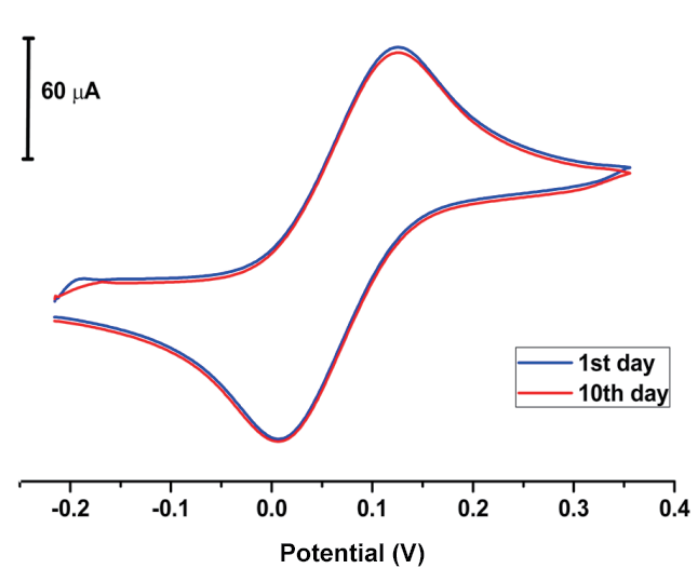

(b)

Fig. 2. (Color online) (a) Cyclic voltammograms of $2 \mathrm{mM}$ ferrocene on GC, CTP, and CTP-DG electrodes in 0.1 $\mathrm{M}$ TBATFB in MeCN with a scan rate of $200 \mathrm{mVs}^{-1} \mathrm{vs} \mathrm{Ag} / \mathrm{Ag}^{+}(0.1 \mathrm{M})$. (b) Cyclic voltammogram of ferrocene on the CTP-DG electrode when it is kept in an open atmosphere for $10 \mathrm{~d}$. 


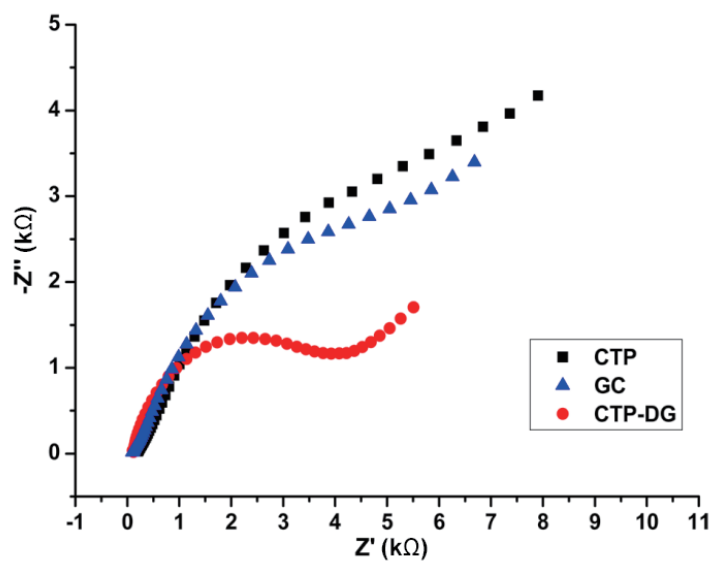

Fig. 3. (Color online) Nyquist plots of $2 \mathrm{mM} \mathrm{K}_{3} \mathrm{Fe}(\mathrm{CN})_{6} / \mathrm{K}_{4} \mathrm{Fe}(\mathrm{CN})_{6}$ in $0.1 \mathrm{M} \mathrm{KCl}$ on the CTP-DG, GC, and CTP electrodes vs $\mathrm{Ag} / \mathrm{AgCl} / \mathrm{KClsat}$. Frequency ranges from $100 \mathrm{kHz}$ to $0.2 \mathrm{~Hz}$ with $10 \mathrm{mV}$ wave amplitude at a DC potential of $75 \mathrm{mV}$ for redox couple.

respectively.

IR measurements were carried out in the wavenumber range of $400-4000 \mathrm{~cm}^{-1}$. FT-IR spectra of the CTP-DG, DG, and CTP electrodes are given in Fig. 4(a). The bands at 3350 and $1050 \mathrm{~cm}^{-1}$ in the IR spectrum of the DG electrode are assigned to the stretching vibrations of $\mathrm{OH}$ and $\mathrm{C}-\mathrm{O}$, respectively. The material has two bands between 3010 and $2790 \mathrm{~cm}^{-1}$ and 1500 and $1350 \mathrm{~cm}^{-1}$ for aliphatic $\mathrm{C}-\mathrm{H}$ stretching and bending, respectively. ${ }^{(24)}$ IR spectra of CTP and CTP-DG are similar. Both materials contain a carbon skeleton. The $\pi$-bonded $\mathrm{C}-\mathrm{H}$ (in alkene and aromatic ring) and aliphatic $\mathrm{C}-\mathrm{H}$ stretching vibrations appear between 3140 and $2790 \mathrm{~cm}^{-1}$. The band of the aliphatic $\mathrm{C}-\mathrm{H}$ stretching of the DG-doped CTP is more intense than the stretching peak of the CTP due to DG, which is only an aliphatic compound. Similarly, the band of the $\pi$-bonded C-H stretching of the CTP is more intense than the stretching peak of CTP-DG. C-H deformation bands are observed between 650 and $1030 \mathrm{~cm}^{-1}$. The aromatic ring modes of both electrodes are observed between 1400 and $1615 \mathrm{~cm}^{-1}$.(25,26)

XPS measurements were carried out on CTP-DG. High-resolution XPS scan for C1s is given in Fig. 4(b). The Cls spectrum was curve-fitted as $\mathrm{sp}^{2}-$ and $\mathrm{sp}^{3}$-hybridized carbons at 284.5 and 286.0 $\mathrm{eV}$, respectively. ${ }^{(27,28)}$ This technique showed that the material includes aliphatic and aromatic/ alkene groups.

XRD patterns of the CTP and CTP-DG are given in Fig. 5. Both materials have two main peaks at 25.3 and $43.1^{\circ}$. The patterns are assigned to the (002) and (100) sequences for carbon atoms. ${ }^{(29)}$ This shows that both materials have a regular form via a thermal process. The pattern of the CTP is sharper than that of CTP-DG. The signal intensity of the glycoside-doped CTP has declined slightly owing to the crystalline form.

SEM images of the CTP and CTP-DG are given in Figs. 6(a) and 6(b), respectively. SEM images were taken from powder form of the solids after a thermal process. The image of the CTP was obtained from a foil-flake form. The image of the CTP shows a regular structure, such as graphene. In Fig. 6(b), the cavities of flakes were filled with DG. The structure of the DG-doped CTP is much more regular than that of the CTP. 


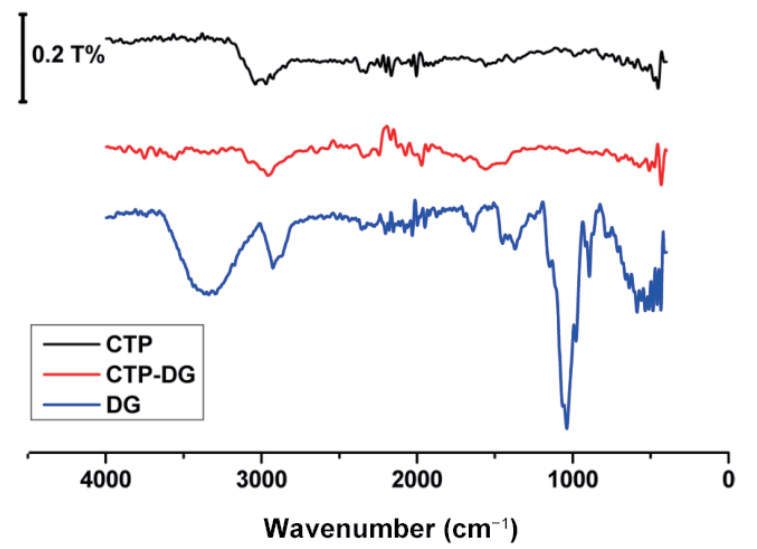

(a)

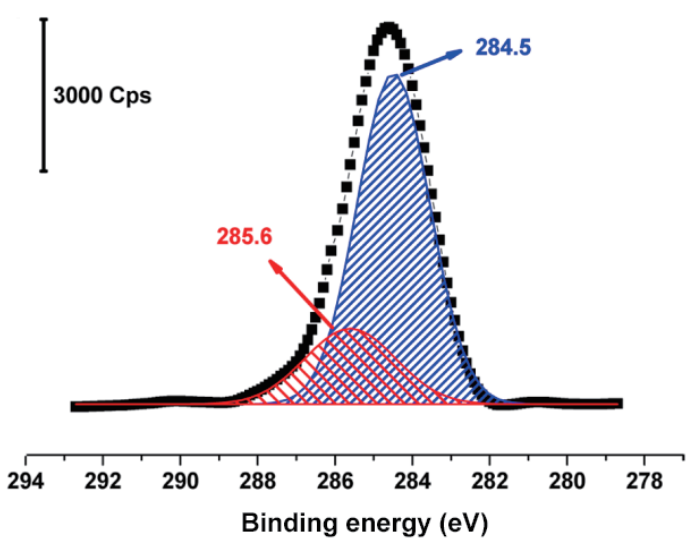

(b)

Fig. 4. (Color online) (a) IR spectra of the CTP-DG and CTP and (b) XPS spectrum of the CTP-DG: highresolution scans for $\mathrm{C} 1 \mathrm{~s}$.

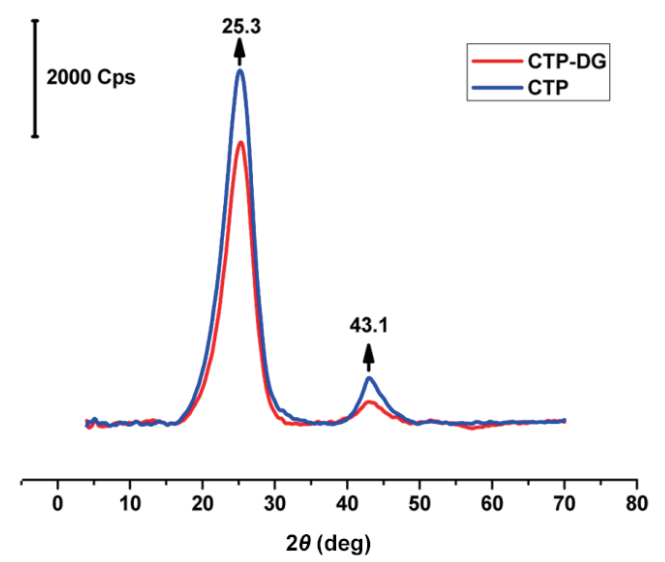

Fig. 5. (Color online) XRD patterns of CTP and CTP-DG.
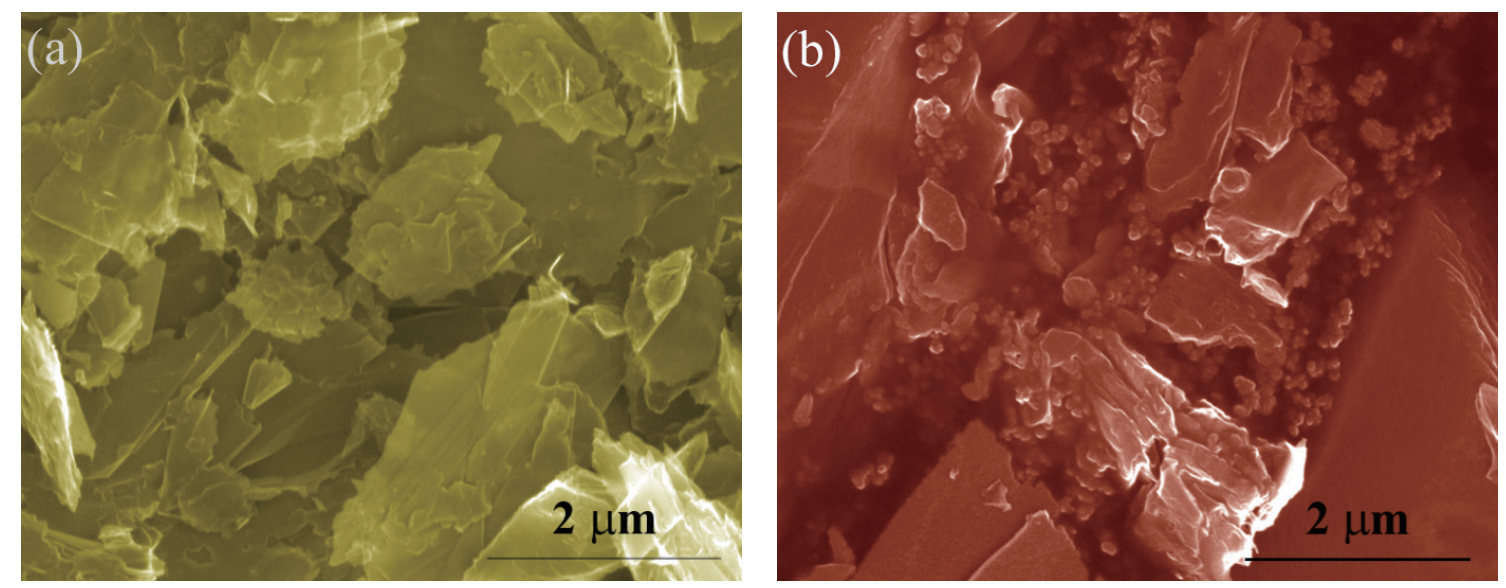

Fig. 6. (Color online) SEM images of (a) CTP and (b) CTP-DG. 


\subsection{Calibration study of $\mathrm{DA}$ in the presence of $\mathrm{AA}$}

Differential pulse voltammograms of DA on the GC, CTP, and CTP-DG electrodes are given in Fig. 7(a). The highest oxidation peak current value was obtained on the CTP-DG. The DPV response of DA on CTP-DG supported the response of the $\mathrm{K}_{3} \mathrm{Fe}(\mathrm{CN})_{6} / \mathrm{K}_{4} \mathrm{Fe}(\mathrm{CN})_{6}$ redox probe on the same electrode. The peak current of $60 \mu \mathrm{M}$ DA on GC, CTP, and CTP-DG was calculated as 9.1, 23.3, and 111.2 $\mu \mathrm{A}$, respectively. The CTP-DG has the highly electrocatalytic effect for DA.

Cyclic voltammograms at various scan rates $(10-300 \mathrm{mV} / \mathrm{s})$ for $0.2 \mathrm{mM}$ DA at the CTP-DG disc electrode are given in Fig. 7(b). CV results showed that the oxidation peak current of DA increased with the scan rate. As shown in Fig. 7, the oxidation peak current was proportional to the square root of the scan rate. The oxidation of DA seemed to be a diffusion-controlled process with $\operatorname{Ip}(\mu \mathrm{A})$ $=6.0023[v]^{1 / 2}-17.075\left(R^{2}=0.9899\right)$.

DPV measurements were performed for DA in the presence of $5 \mathrm{mM}$ AA in PBS (pH: 7). The concentration range of DA was 1-60 $\mu \mathrm{M}$. Figure $8(\mathrm{a})$ shows the DPV recordings at various concentrations of DA at the CTP-DG disc electrode. The peak potentials of AA and DA were found as -37 and $148 \mathrm{mV}$, respectively. The linear response to DA in the range of 1 to $60 \mu \mathrm{M}$ is given in Fig. 8(b). The linear equation for DA was $I p_{(\mathrm{DA})}=1.7297[\mathrm{DA}]+4.8984\left(R^{2}: 0.9961\right)$ with the linear range of 1 to $60 \mu \mathrm{M}$. The LOD is $0.08 \mu \mathrm{M}$.

The various LODs obtained with the developed sensor are compared with those of the other reported methods. The results are given in Table 1. The developed electrode could provide a good platform for the effective electroanalytical detection.

\subsection{Precision and accuracy results of the method}

Three different DA concentrations $(2.0,5.0$, and $7.0 \mu \mathrm{M})$ in the linear range were analyzed in five independent series on the intraday and interday. The results are given as data percentages in

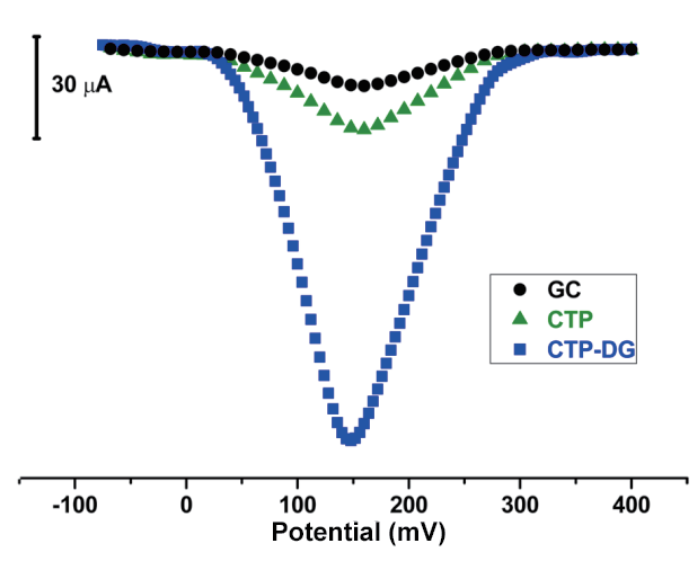

(a)

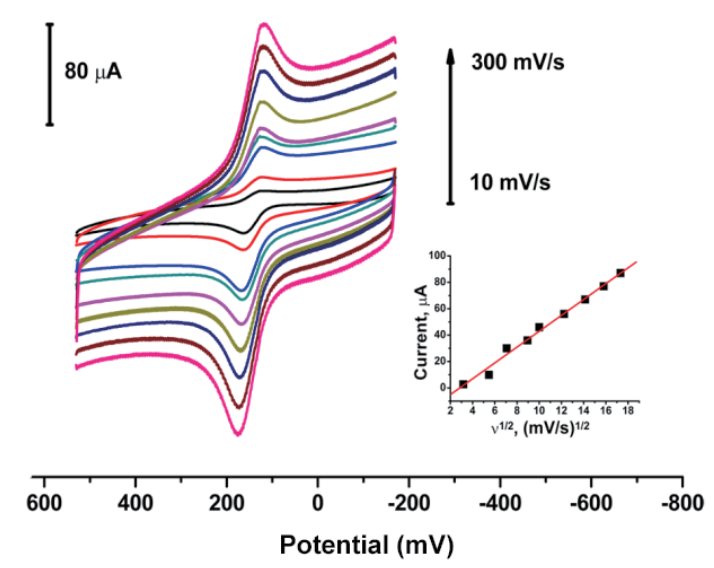

(b)

Fig. 7. (Color online) (a) DPVs of $60 \mu \mathrm{M}$ DA on GC, CTP, and CTP-DG, and (b) CV results of $0.2 \mathrm{mM}$ DA on CTP-DG at various scan rates $(10-300 \mathrm{mV} / \mathrm{s})$ in a $0.1 \mathrm{M}$ PBS $(\mathrm{pH} 7.0)$ and their linear curve between the current of the oxidation peak and the square root of the scan rate. 


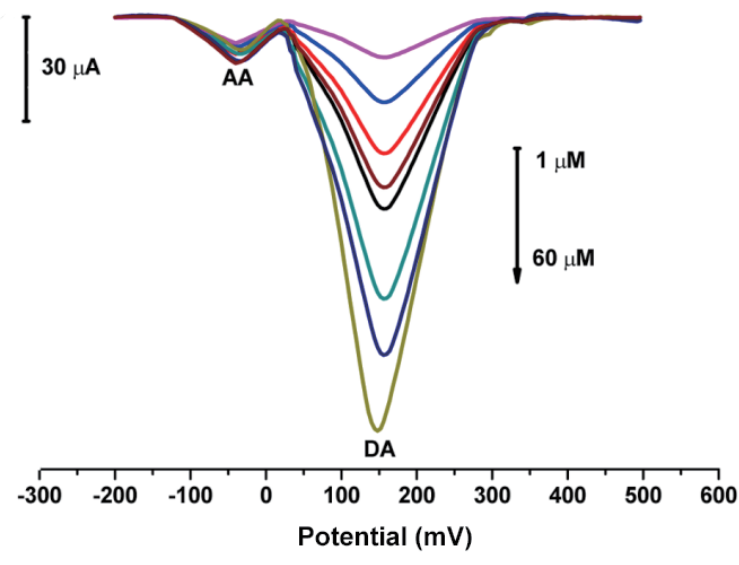

(a)

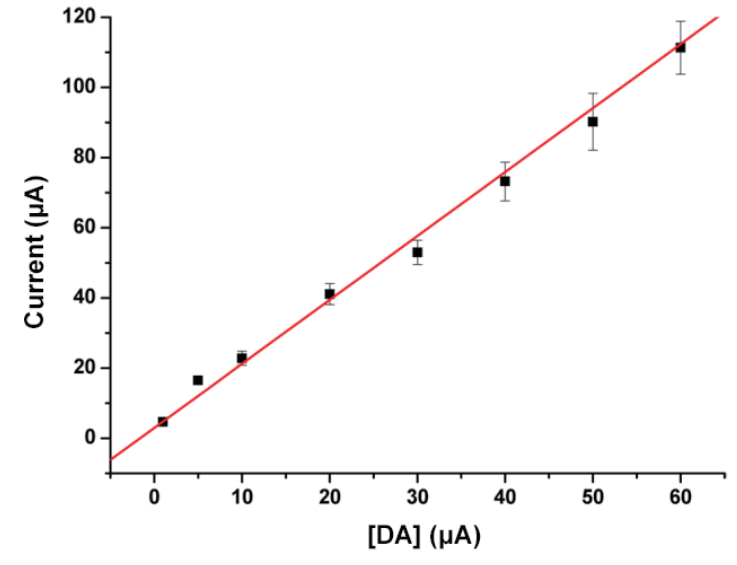

(b)

Fig. 8. (Color online) (a) DPVs of 1-60 $\mu \mathrm{M}$ DA on CTP-DG in the presence of AA and (b) their calibration curve.

Table 1

Responses of various voltammetric sensors to DA.

\begin{tabular}{lccc}
\hline \multirow{2}{*}{ Electrode } & \multicolumn{2}{c}{ Calibration $(\mu \mathrm{M})$} & \multirow{2}{*}{ Reference } \\
\cline { 2 - 3 } & $0.6-1000$ & 0.19 & 30 \\
ERGO-FA/GCE & $4-100$ & 2.64 & 31 \\
Graphene & $0.5-100.0$ & 0.31 & 32 \\
MWCNT/CCE & $0.5-2000$ & 0.12 & 33 \\
SPGNE & $1.0-210$ & 0.08 & 34 \\
AuNCs/AGR/MWCNT/GCE & $0.06-2.03$ & 0.05 & 35 \\
PtNPs-MWCNT/GCE & $1.0-200$ & 0.3 & 36 \\
RGO-AuNPs-CSHMs & $2.0-1500$ & 1.0 & 37 \\
CILE & $0.1-8.5$ & 0.024 & 38 \\
s-GONR-GCE & $0.5-20$ & 0.1 & 39 \\
PIn5COOH & $1-60$ & 0.08 & This study \\
CTP-DG & &
\end{tabular}

ERGO-FA/GCE: electrochemically reduced graphene oxide-ferulic acid, MWCNT/CCE: multiwall carbon-nanotubemodified carbon-ceramic electrode, SPGNE: screen-printed graphene electrode, AuNCs/AGR/MWCNT: gold nanoclusters/ activated graphene multiwall carbon-nanotube nanocomposite, PtNPs-MWCNT/GCE: Pt nanoparticles decorating multiwall carbon-nanotube-modified glassy carbon electrode, RGO-AuNPs-CSHMs: reduced graphene oxide and Au nanoparticles entrapped in chitosan/silica sol-gel hybrid membranes, CILE: carbon ionic liquid electrode, s-GONR-GCE: short graphene oxide-nanoribbon-modified GC electrode, and PIn5COOH: poly(indole-5-carboxylic acid) electrode.

Table 2

Precision and accuracy results of the method.

\begin{tabular}{lcccc}
\hline \multirow{2}{*}{ Found Value, precision \% (RSD), and accuracy \% } & \multicolumn{3}{c}{ Added (DA) } \\
\cline { 2 - 5 } & Found Value & $2 \mu \mathrm{M}$ & $5 \mu \mathrm{M}$ & $7 \mu \mathrm{M}$ \\
\hline \multirow{2}{*}{ Intraday $^{*}$} & RSD \% & $2.01 \pm 0.02$ & $5.04 \pm 0.03$ & $7.06 \pm 0.05$ \\
& Accuracy \% & 1.00 & 0.60 & 0.71 \\
& Found Value & 0.50 & 0.80 & 0.86 \\
\hline \multirow{2}{*}{ Interday $^{*}$} & RSD \% & $1.00 \pm 0.03$ & $4.98 \pm 0.02$ & $7.11 \pm 0.06$ \\
& Accuracy \% & 0 & 0.40 & 0.84 \\
& & -0.40 & 1.57 \\
\hline
\end{tabular}

${ }^{*}$ Five independent series on the same day for intraday precision and five consecutive days for interday precision from five measurements of every series. 
Table 3

Effects of some groups on the peak currents of $1 \mu \mathrm{M}$ DA in 0.1 M PBS (pH 7.0).

\begin{tabular}{lcc}
\hline Interferences & $\begin{array}{c}\text { Concentration } \\
(\mu \mathrm{M})\end{array}$ & \begin{tabular}{c} 
Signal change of DA \\
\cline { 3 - 3 }
\end{tabular} \\
\hline $\mathrm{Na}^{+}$ & 1000 & $-3.67 \%$ \\
$\mathrm{~K}^{+}$ & 1000 & $-2.01 \%$ \\
$\mathrm{NH}_{4}^{+}$ & 1000 & $2.03 \%$ \\
$\mathrm{Mg}^{++}$ & 1000 & $-1.27 \%$ \\
$\mathrm{Zn}^{2+}$ & 1000 & $2.46 \%$ \\
$\mathrm{Cl}^{-}$ & 1000 & $-2.28 \%$ \\
$\mathrm{NO}_{3}{ }^{-}$ & 1000 & $-0.20 \%$ \\
$\mathrm{SO}_{4}{ }^{2-}$ & 1000 & $4.43 \%$ \\
$\mathrm{Uric}^{-}$acid & 200 & $-0.55 \%$ \\
Folic acid & 200 & $0.47 \%$ \\
D-glucose & 1000 & $0.21 \%$ \\
L-alanine & 1000 & $0.97 \%$ \\
Aspartic acid & 1000 & $0.55 \%$ \\
\hline
\end{tabular}

Table 4

Analytical recovery of DA from urine samples $(N=5)$.

\begin{tabular}{cccc}
\hline Sample & $\begin{array}{c}\text { Added DA } \\
(\mu \mathrm{M})\end{array}$ & $\begin{array}{c}\text { Detected by } \\
\text { DPV }(\mu \mathrm{M})\end{array}$ & $\begin{array}{c}\text { Recovery } \\
(\%)\end{array}$ \\
\hline \multirow{4}{*}{ Urine I } & - & - & - \\
& 5 & 4.98 & 99.6 \\
& 10 & 10.07 & 100.7 \\
& 20 & 20.71 & 103.6 \\
\hline
\end{tabular}

\begin{tabular}{cccc}
\hline \multirow{4}{*}{ Urine II } & - & - & - \\
& 5 & 5.12 & 102.4 \\
& 10 & 9.88 & 98.8 \\
& 20 & 20.04 & 100.2 \\
\hline \multirow{4}{*}{ Urine III } & - & - & - \\
& 5 & 5.02 & 100.2 \\
& 10 & 10.33 & 103.3 \\
& 20 & 19.81 & 99.05 \\
\hline
\end{tabular}

Table 2. The precision values (RSD \%) varied from 0.60 to 1.00 for intraday precision and from 0.40 to 1.50 for interday precision. The accuracy of the developed method was calculated as the percent of relative error. The accuracy values (\%) varied from 0.50 to 0.86 for intraday precision and from 0 to 1.57 for interday precision. Results were calculated within the acceptable limits.

\subsection{Interference}

The effects of some important biological substances and ions on the peak currents of $1 \mu \mathrm{M}$ DA in $0.1 \mathrm{M}$ PBS ( $\mathrm{pH}$ 7.0) are given in Table 3. Current signal changes are approximately $\leq 4.43$ and $\geq-3.67 \%$. Therefore, in the interference study, the interference effect of these groups in the selected concentration range is not an important factor.

\subsection{Determination of DA in human urine samples}

We determined DA in three human urine samples using the standard addition method to evaluate the validity and reliability of the proposed method. The samples were diluted 50 times using PBS (0.1 M, pH 7.0). DPV results were recorded after $200 \mu \mathrm{L}$ of urine sample was added into $10 \mathrm{~mL}$ of the buffer solution. The measurements are presented in Table 4. The recovery of the samples ranged between 98.8 and $103.6 \%$. The results showed the successful application of the CTP-DG carbonaceous electrode to the determination of DA in urine samples.

\section{Conclusions}

A carbonized CTP-DG disc electrode was prepared with the pyrolysis of a DG-CTP mixture. The electrode materials were characterized by CV, EIS, XPS, IR, XRD, and SEM. The electrode was pressed into thick pellets. This electrode was used for the determination of DA in the presence of AA via DPV. The electron transfer rate of DA significantly increased via the electrocatalytic 
effect on the CTP-DG electrode. The linear equation for DA was $I p_{(\mathrm{DA})}=1.7297[\mathrm{DA}]+4.8984\left(R^{2}\right.$ : $0.9961)$ with the linear range of 1 to $60 \mu \mathrm{M}$ in the presence of $5 \mathrm{mM}$ AA. The LOD $(S / N=3)$ of the developed method was $0.08 \mu \mathrm{M}$. Accuracy and precision were calculated within acceptable limits. The developed method was applied to human urine samples. The maximum analytical recovery of DA via the method added to urine samples was calculated as $\leq 103.6 \%$.

\section{References}

1 J. C.-García and C. R. Cabrera: Electrocatalysis 5 (2014) 402.

2 S. Majdi, A. Jabbari, H. Heli, H. Yadegari, A. A. Moosavi-Movahedi, and S. Haghgoo: J. Solid State Electrochem. 13 (2009) 407.

3 V. E. Norvell and G. Mamantov: Anal. Chem. 49 (1977) 1470.

4 A. J. Gross and A. J. Downard: Anal. Chem. 83 (2011) 2397.

5 Y. Wen, J.-S. Ye, W.-D. Zhang, F.-S. Sheu, and G. Q. Xu: Microchim. Acta 162 (2008) 235.

6 A. B. M. Zakaria, E. S. Vasquez, K. B. Walters, and D. Leszczynska: RSC Adv. 5 (2015) 107123.

7 Y. Gao, L. Li, Y. Jin, Y. Wang, C. Yuan, Y. Wei, G. Chen, J. Ge, and H. Lu: Appl. Energy 153 (2015) 41.

8 V. Selvamani, R. Ravikumar, V. Suryanarayanan, D. Velayutham, and S. Gopukumar: Electrochim. Acta 182 (2015) 1

9 Y. Fan, P.-F. Liu, Z.-J. Yang, T.-W. Jiang, K.-L. Yao, R. Han, X.-X. Huo, and Y.-Y. Xiong: Electrochim. Acta 163 (2015) 140.

10 Z. Wang, S. Zhang, L. Zhang, R. Lin, X. Wu, H. Fang, and Y. Ren: J. Power Sources 248 (2014) 337.

11 Y. Li, H. Zhang, P. Liu, Y. Wang, H. Yang, Y. Li, and H. Zhao: Electrochem. Commun. 51 (2015) 6.

12 V. Flexer, N. Brun, R. Backov, and N. Mano: Energy Environ. Sci. 3 (2010) 1302.

13 W. Lv, F. Wen, J. Xiang, J. Zhao, L. Li, L. Wang, Z. Liu, and Y. Tian: Electrochim. Acta 176 (2015) 533.

14 F. Montilla, E. Morallón, J. L. Vázquez, J. A.-Monge, D. C.-Amorós, and A. L.-Solano: Carbon 40 (2002) 2193.

15 Y.-X. Wang, S.-L. Chou, J. H. Kim, H.-K. Liu, and S.-X. Dou: Electrochim. Acta 93 (2013) 213.

16 H. Liu, T. Li, X. Wang, W. Zhang, and T. Zhao: J. Anal. Appl. Pyrolysis 110 (2014) 442.

17 X.-J. He, X.-J. Li, X.-T. Wang, N. Zhao, M.-X. Yu, and M.-B. Wu: New Carbon Mater. 29 (2014) 493.

18 M. Yamaoka, S.-S. Asami, N. Funaki, S. Kimura, L. Yingjie, T. Fukuda, and M. Yamashita: PLoS One 8 (2013) e62903/1.

19 C. Blanco, R. Santamaría, J. Bermejo, and R. Menéndez: Carbon 38 (2000) 517.

20 L. Hao, X. Li, and L. Zhi: Adv. Mater. 25 (2013) 3899.

21 S. Basu and P. S. Dasgupta: J. Neuroimmunol. 102 (2000) 113.

22 X. Ouyang, L. Luo, Y. Ding, B. Liu, D. Xu, and A. Huang: J. Electroanal. Chem. 748 (2015) 1.

23 A. Erkal, M. S. Erdoğan, İ. Aşık,H. Ekşi, S. Jeon, A. O. Solak, and Z. Üstündağ: J. Electrochem. Soc. 161 (2014) H696.

24 J. A.-Monge and D. C.-Amorós: Fuel 80 (2001) 41.

25 M. E.-Gemayel, A. Narita, L. F. Dössel, R. S. Sundaram, A. Kiersnowski, W. Pisula, M. R. Hansen, A. C. Ferrari, E. Orgiu, X. Feng, K. Müllen, and P. Samorì: Nanoscale 6 (2014) 6301.

26 Y. I. Kurys, O. O. Ustavytska, V. G. Koshechko, and V. D. Pokhodenko: Electrocatalysis 6 (2015) 117.

27 S.-K. Jerng, D. S. Yu, J. H. Lee, C. Kim, S. Yoon, and S.-H. Chun: Nanoscale Res. Lett. 6 (2011) 565.

28 A. Erkal, İ. Üstündağ, S. Yavuz, and Z. Üstündağ: J. Electrochem. Soc. 162 (2015) H213.

29 Z. Guo, C. Wang, M. Chen, and M. Li: Int. J. Electrochem. Sci. 8 (2013) 2702.

30 H. S. Han, H. Seol, D. H. Kang, M. S. Ahmed, J.-M. You, and S. Jeon: Sens. Actuators, B 204 (2014) 289.

31 C. Xiao, X. Chu, Y. Yang, X. Li, X. Zhang, and J. Chen: Biosens. Bioelectron. 26 (2011) 2934.

32 B. Habibi and M. H. P.-Azar: Electrochim. Acta 55 (2010) 5492.

33 J. Ping, J. Wu, Y. Wang, and Y. Ying: Biosens. Bioelectron. 34 (2012) 70.

34 A. A. Abdelwahab and Y.-B. Shim: Sens. Actuators, B 221 (2015) 659.

35 Z. Dursun and B. Gelmez: Electroanalysis 22 (2010) 1106.

36 X. Liu, L. Xie, and H. Li: J. Electroanal. Chem. 682 (2012) 158.

37 A. Safavi, N. Maleki, O. Moradlou, and F. Tajabadi: Anal. Biochem. 359 (2006) 224.

38 C. L. Sun, C. HaoSu, and J. JhouWu: Biosens. Bioelectron. 67 (2015) 327.

39 J. Maciejewska, K. Pisarek, I. Bartosiewicz, P. Krysinski, K. Jackowska, and A. T. Biegunski: Electrochim. Acta 56 (2011) 3700 . 